\title{
A k-means clustering for supply chain risk management with embedded network connectivity
}

\author{
Xiao Feng Yin*, Xiuju Fu, \\ Loganathan Ponnambalam and \\ Rick Siow Mong Goh
}

Computing Science Department, Institute of High Performance Computing,

1 Fusionopolis Way,

\#16-16 Connexis, 138632, Singapore

Email: yinxf@ihpc.a-star.edu.sg

Email: fuxj@ihpc.a-star.edu.sg

Email: ponnaml@ihpc.a-star.edu.sg

Email: gohsm@ihpc.a-star.edu.sg

*Corresponding author

\begin{abstract}
In recent years, increased attention has been shown to the supply chain risk management due to the occurrences of several high profile disruptions which resulted in significant social, economic and political impact globally. However, there are not direct and easy ways of understanding the risk of an entire supply chain. In this paper, a network connectivity embedded $\mathrm{k}$-means clustering approach has been proposed to determine at-risk clusters of nodes that share similar risk profiles and linkages with the focal company. It uses a multiple dimensional feature vector to represent the risks that nodes are facing, their geographical locations, supply chain attributes and network connectivity attributes. The clustering approach is able to reduce the complexity of a large supply chain network to facilitate in-depth targeted analysis and simulations. The effectiveness of the proposed approach has been illustrated by experiments that successfully identify the risk clusters and critical risk zones.
\end{abstract}

Keywords: supply chain risk management; supply chain risk clustering; k-means clustering.

Reference to this paper should be made as follows: Yin, X.F., Fu, X., Ponnambalam, L. and Goh, R.S.M. (2016) 'A k-means clustering for supply chain risk management with embedded network connectivity', Int. J. Automation and Logistics, Vol. 2, Nos. 1/2, pp.108-121.

Biographical notes: Xiao Feng Yin received both his $\mathrm{PhD}$ and his Master's degrees from Nanyang Technological University (NTU), Singapore. His research areas include logistics and supply chain optimisation, planning and scheduling, knowledge discovery and artificial intelligence. He was a research staff of NTU from 2010 to 2012, working on projects of knowledge discovery and anomaly detection. He is currently working in IHPC Singapore as a research scientist in supply chain risk management and logistics optimisation. 
Xiuju Fu received her $\mathrm{PhD}$ degree from Nanyang Technological University (NTU), Singapore in 2003 and both of her Master and Bachelor degrees are from Beijing Institute of Technology, China. Her research areas include data mining, network analytics, optimisation, agent-based modelling and simulation and applications to logistics and supply chain management, maritime optimisation, public health system management and infectious disease spread mitigation. She currently works in Institute of High Performance Computing, Singapore as a Senior Research Scientist in Department of Computing Science.

Loganathan Ponnambalam is a Research Scientist in the Computing Science Department at the Institute of High Performance Computing, A*STAR, Singapore. He obtained his PhD from National University of Singapore (NUS) in 2013. His research primarily focuses on using agent-based models for supply chain disruption modelling and infectious disease policy planning. His other research interests include network analytics for resource allocation, maritime traffic management and spatio-temporal modelling.

Rick Siow Mong Goh is the Director of the Computing Science Department at the A*STAR Institute of High Performance Computing (IHPC). At IHPC, he leads a team of more than 50 scientists in performing world-leading scientific research, developing technologies to commercialisation, and engaging and collaborating with industry. The research focus areas include high performance computing (HPC), distributed computing, big data analytics, intuitive interaction technologies, and complex systems. His expertise is in discrete event simulation, parallel and distributed computing, and performance optimisation and tuning of applications on large-scale computing platforms. $\mathrm{He}$ received his $\mathrm{PhD}$ in Electrical and Computer Engineering from the National University of Singapore.

This paper is a revised and expanded version of a paper entitled 'A network connectivity embedded clustering approach for supply chain risk assessment' presented at the 18th Asia Pacific Symposium on Intelligent and Evolutionary Systems, Singapore, 10-12 November 2014.

\section{Introduction}

The supply chain risk management has received an increasing global attention in recent years owning to huge impacts from occurrences of some high profile disruptions across the world. Risks and disruptions including earthquakes, economic crises, strikes and terrorist attacks have repeatedly hit the supply chain and its operations. In addition, due to the globalisation and constant adoption of practices such as outsourcing, drop shipment and vendor management inventory, it is important for a company to keep track of happenings of potential risks in its entire supply chain network including disasters and social unrest around the regions of its key suppliers as they may have eventually an impact on the focal company itself. The appropriate management of constraints of the supply, manufacturing, and demand and relevant risks is essential for the sustainable development and business success of a company (Tang, 2006; Tang and Musa, 2011; Bearzotti et al., 2012).

The recent catastrophic events like flood in Thailand, earthquake in Japan demonstrated that the effects of the natural disruption not only had its impact at the place of its origination, but also propagated to the other entities of the supply chain. Therefore, 
the risk management and mitigation process should consider the whole supply chain network while more attentions shall be paid to the risk zones. Disaster-related risks and disruptions normally are with low probability but low predictability. This leaves company's insufficient time to react that may cause widespread business disruptions (CFO Research Services, 2013) like:

1 damaging facilities

2 upending shipping schedules

3 interfering with production

4 impairing the ability to meet customers' expectations for high quality and timely services.

Taking the 2010 volcanic eruption of Eyjafjallajökull in Iceland as an example, it caused enormous disruption to air travel across western and northern Europe over an initial period of six days in April 2010. Big global company such as Infineon's DC in Europe (DCE) was badly affected as delivery of products to customers is usually through air. DCE had to resort to land transportation by trucks to clear the backlogs while the customer service had to be compromised due to longer delivery time.

The empirical analysis in automotive industry conducted by Thun and Hoenig (2011) revealed that the rising complexity and increasing uncertainties and dependencies among companies fostered supply chain risk and resulted in increased supply chain vulnerability and poorer visibility. Tang (2006) had reviewed various quantitative models for managing supply chain risks. He concluded that those quantitative models were designed for managing operational risks primarily, not disruption risks, due to inaccurate measures of the probability of an occurrence of a major disruption and the potential impact of a disruption in a large supply chain network. There are not direct and easy ways of understanding the risk of an entire supply chain.

The Thailand flood during 2011 resulted in a global shortage of hard disk supply due to the overly centralised hard disk manufacturers over the area that was badly affected. If such a risk cluster of the supply chain network can be identified earlier, mitigated precautions can be taken to source more suppliers from other regions or mitigation plans can be studied and prepared.

\section{Supply chain risk clustering}

Today's supply chains are presented more as complex networks in the globalised environment, which are highly interlinked leading to highly sophisticated structures and also increased vulnerability to many supply chain risks. Analysis of such networks such as its dynamics, structure and semantics is usually challenging for detecting patterns and trends in supply chain networks, for making wise business decisions under the stress posed by supply chain risks.

Thus in this paper, a supply chain risk clustering approach is proposed to handle supply chain risk management. It starts from a real-time event tracking and risk monitoring. Equipped with the necessary risk information, the essence of the clustering problem is to develop a methodology for determining groups of 'similar' nodes that can be treated as a basic unit for tactic and strategic analysis of supply chain network. The 
risk clustering is capable of reducing the complexity of a large supply chain network and identifying topological risks in supply chain networks. It is to facilitate the evaluations of potential at-risk facilities and clusters hidden in supply chain networks that cannot be easily detected. Besides, targeted measurements, analysis and simulations can be designed and employed to a specific cluster of supply chain after the clusters have been determined. By doing so, better results and performances can be expected.

Clustering technology had been utilised in many researches to simplify the supply chain network and assist the decision-making. Irfan et al. (2007) proposed a k-means algorithm to find the cluster centres of different supply chain tiers, such as customers, retailers, distribution centres and manufacturers, to assist the business decisions. In order to simplify the supply chain and production network, Doring et al. (2007) worked on a $\mathrm{k}$-means clustering approach for grouping of state spaces of production network. Hu et al. (2009) applied neural network-based fuzzy clustering to study the supply chain quality management while considering macro variables such as:

1 political influence and law and regulation

2 micro variables such as price and quantity.

In order to reduce the complexity of an extended supply chain network for planning and scheduling, Yin et al. (2013) proposed a hybrid evolutionary approach to the clustering of supply chain by considering material flow and the total cost. Tabrizi and Razmi (2013) applied fuzzy set theory to understand the extant uncertainties and risks during the phase of supply chain network design.

There were few studies addressing the supply chain risk clustering. Hallikas et al. (2005) explored the network risks, risk-management measures and supplier classification to achieve collaborative risk management and learning. A work had also been carried out by Reniers et al. (2012) to understand the systemic risk that took into consideration the safety and security index and the supply chain index of a typical supply chain cluster in chemical industry. It built upon an established cluster network. The holistic analysis that takes into consideration connectivity, geographical lactation and supply chain risk in supply chain risk management context to facilitate the evaluations of potential at-risk facilities and clusters and assess the overall risk that a company faces is lacking.

This paper is an extended version from Yin et al (2015) at IES 2015 for the special issue of the conference with additional work on event tracking and monitoring and case study. In the rest of the paper, Section 3 discusses the event tracking and risk monitoring. A network connectivity embedded k-means clustering algorithm is depicted in Section 4, followed by the experiments and discussions in Section 5. The main conclusions reached in this work and future work is then summarised in the last section, Section 6.

\section{Event tracking and risk monitoring}

When a severe disaster takes place, such as storm, earthquake and flooding, it disrupts infrastructure, logistics, and manufacturing and communication systems. It may immediately cause the loss of business revenues and opportunities due to the disruption on company supply chain operations. The event tracking and risk monitoring consists of: 
1 an online heat map searching engine, which provides the information of historical risk scores and events of different locations to assist companies to assess robustness of their supply chain networks

2 event monitoring engine, which monitors real-time incidents for assisting prompt responses to disruptions and monitoring recovery processes, etc.

Natural or man-made disaster events can be collected through open source intelligence applications and monitored constantly. Real-time alerts can then be raised for evaluating critical risks that a focal company is facing. The captured knowledge can be applied to perform functions of proactive monitoring and reactive investigation, in conjunction with the supply chain data repository and web-bots for real-time data sharing.

1 Proactive monitoring: the event tracking and risk monitoring module actively monitors the internet and the focal company's supply chain for anomalous information contents related to the disruptions and potential supply chain risks including natural disaster, market fluctuation risk and others. Upon instruction, the intelligent system will constantly patrol the internet to dig information related to specific subjects, deliver regular summary reports, and raise alerts where necessary.

2 Reactive investigation: after potential disruptions and risks to the supply chain are raised, it can be highlighted for the supply chain with key nodes or sub-network in the affected regions and locations. More relevant information regarding the disruption and the particular region will be captured for investigation.

Figure 1 Natural disaster tracking and monitoring (see online version for colours)

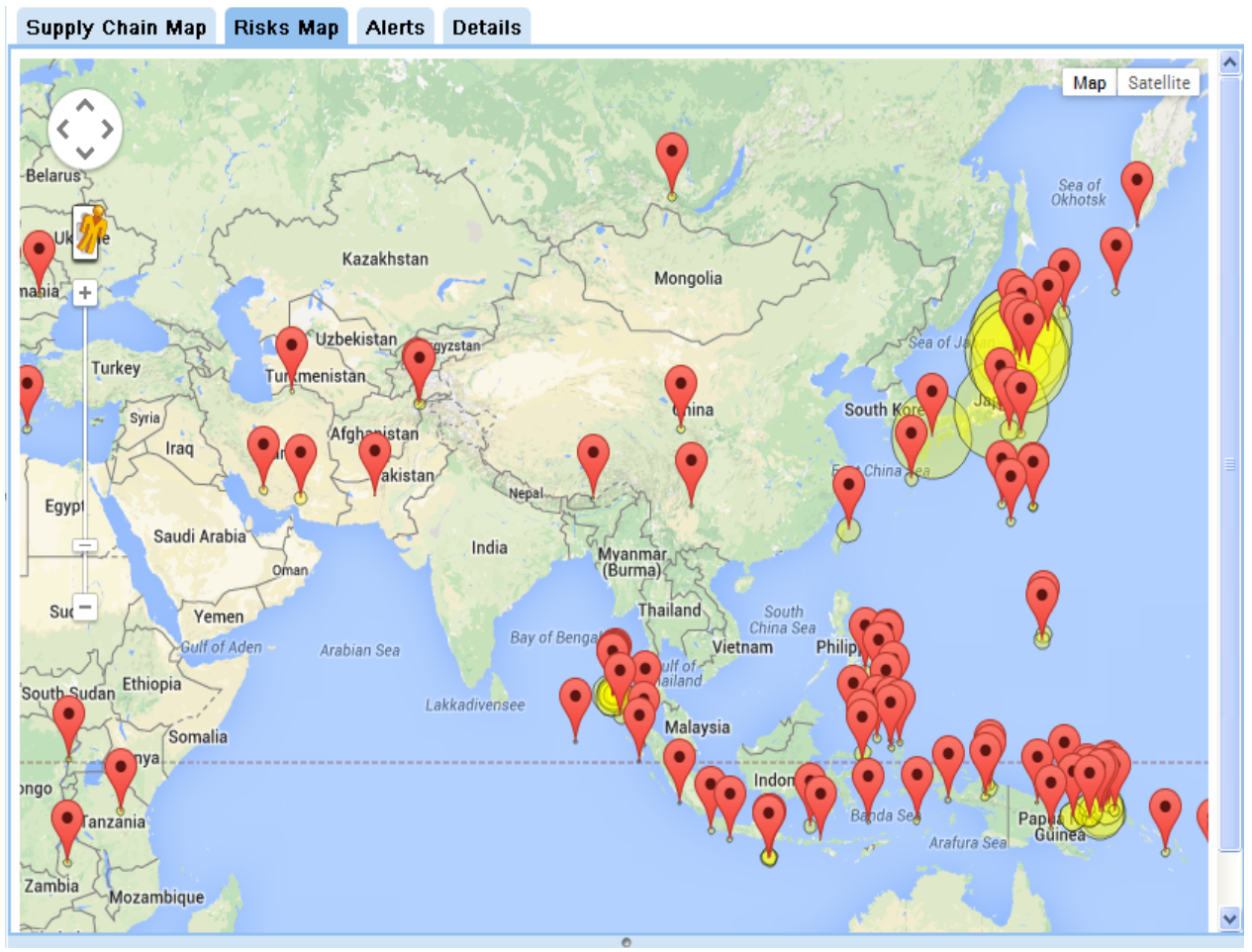


Figure 2 Natural disaster tracking and monitoring (see online version for colours)

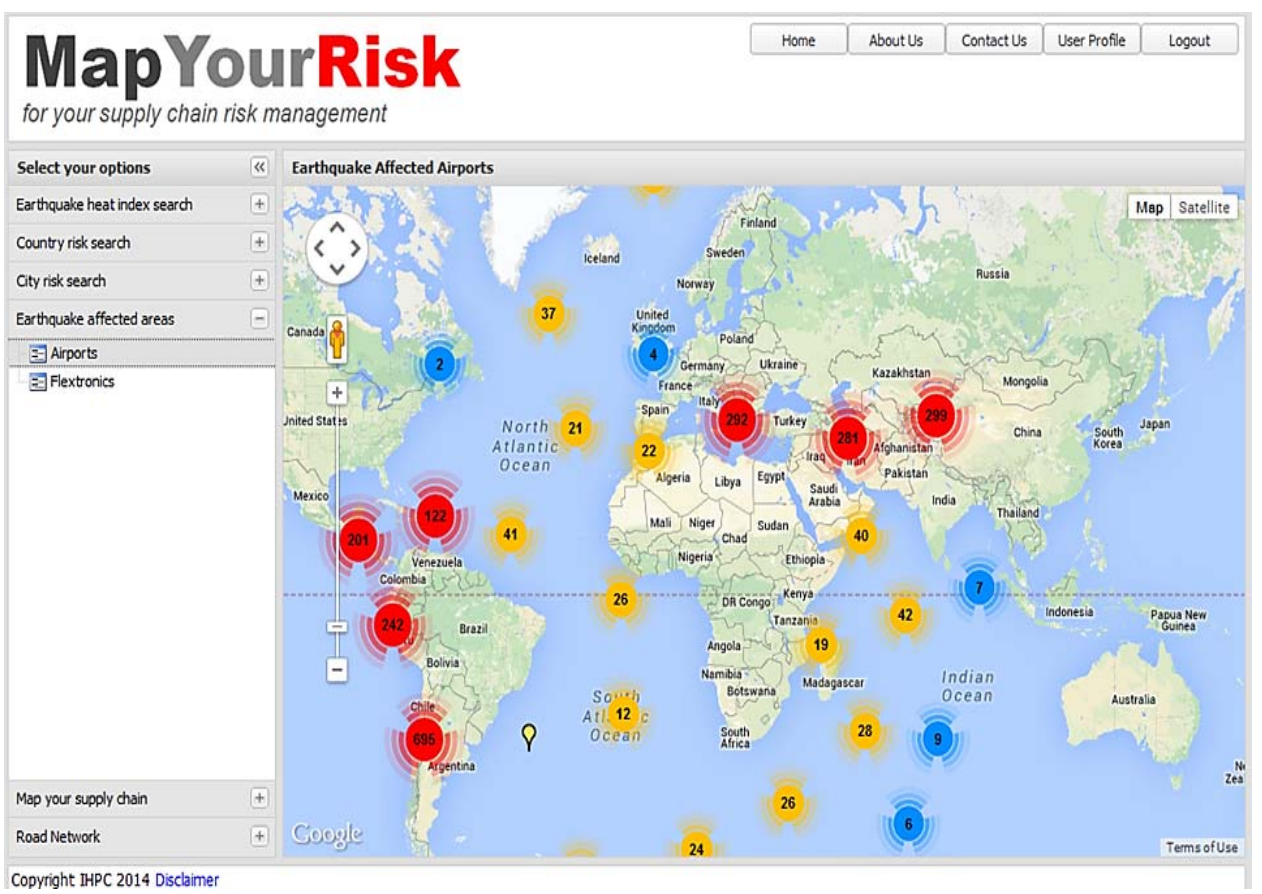

Figure 3 Risk scores of country (see online version for colours)

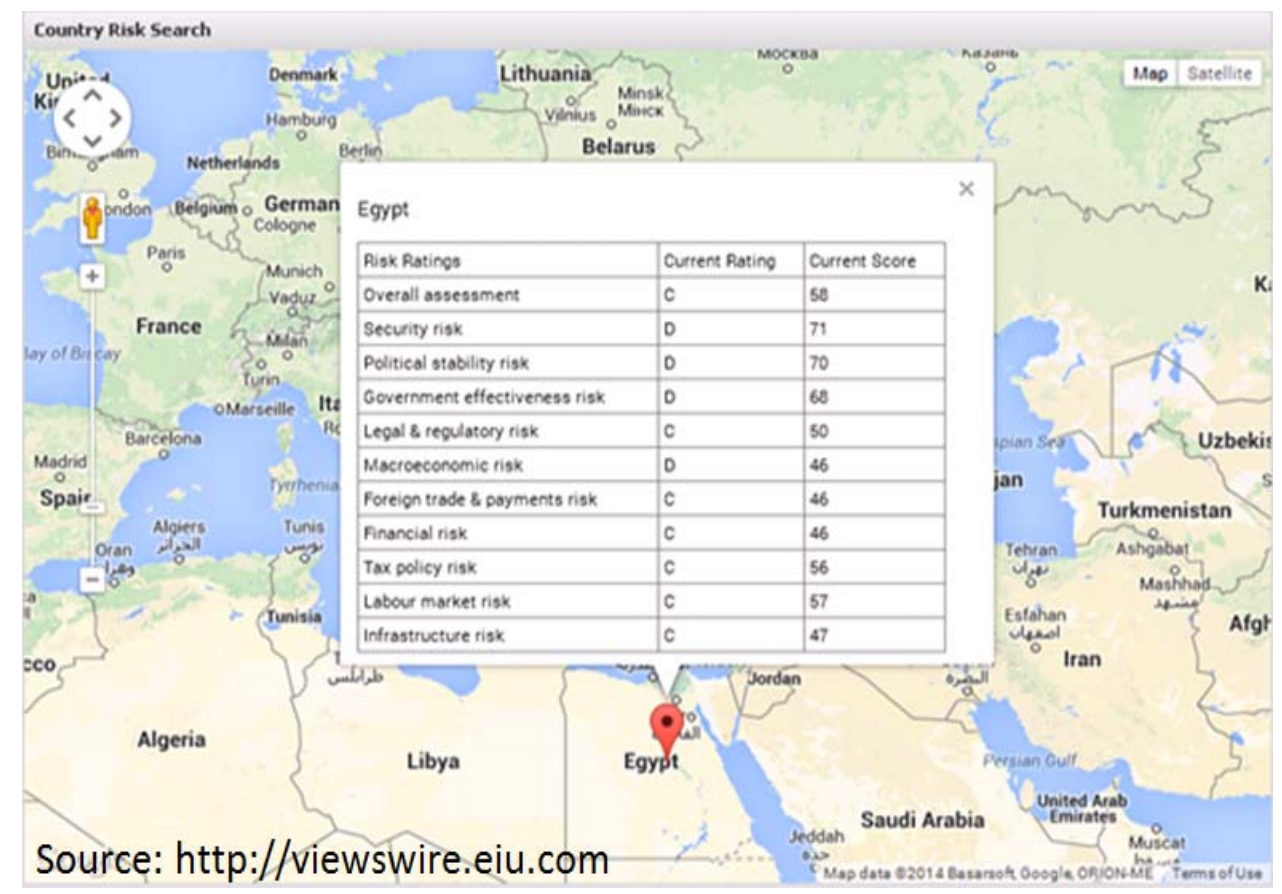


Figure 1 shows the natural disasters and geographical location data captured in real-time basis while the severity of impact is represented by the size of the circle. Furthermore, a study on the impact to the infrastructure has been carried out in respect to the natural disaster. Figure 2 illustrates the potential impact to the airports all over the world due to the natural disasters captured. As the key chain for logistics, a badly affected airport may incur severe delays on the delivery of cargos of the region. Coupled with the risk scores of country (Figure 3 ) and city and the physical supply chain network topology, it gives researches a great potential to investigate the risk levels and risk clusters of a supply chain network. As such, it is able to better support the decision-making or action taken to mitigate the disruption that could enable the smooth and effective handling of disruption.

A system named 'MapYourRisk' has been developed to actively collect data from different sources. It includes the following data.

- $\quad$ natural disaster, e.g., earthquake

- company locations and financial records

- $\quad$ country and city risk scores

- $\quad$ supply chain network.

The data collection is extending to other non-structured data sources, such as news reports, company annual reports, etc. The information is then normalised and risk scores are calculated for the supply chain facilities along a supply chain network.

\section{A network connectivity embedded k-means clustering}

\subsection{Problem description}

Given a supply chain network and a set of nodes of the network $X=\left\{X_{1}, X_{2}, \ldots, X_{n}\right\}$ where each node $X_{i}$ is a multiple dimensional feature vector representing the supply chain and related attributes to be considered, the clustering algorithm needs to partition the $n$ nodes into $k$ clusters with centroids of clusters $C=\left\{C_{1}, C_{2}, \ldots, C_{k}\right\}$ so as to minimise the squared error as expressed in equation (1).

$$
\arg \min \sum_{j=1}^{k} \sum_{i=1, y_{i}=j}^{n}\left\|X_{i}-C_{j}\right\|^{2}
$$

where

$y_{i} \quad$ cluster assignment of node $X_{i}, i=1,2, \ldots, n$

$C_{j} \quad$ centroid of cluster $j, j=1,2, \ldots, k$.

Cluster assignment $y_{i}$ can be established given the centroids of the clusters using equation (2) as follows.

$$
y_{i}=\arg \min \left\|X_{i}-C_{j}\right\|^{2}
$$




\subsection{Mathematical model-a generic model for supply chain risk clustering}

As mentioned in Section 4.1, node $X_{i}$ is a multiple dimensional feature vector. It represents the risks of a node facing, the geographical location, supply chain attributes and network connectivity attributes. By considering the above supply chain and risk specific features, equations (3) and (4) can be derived to represent $X_{i}$ and $C_{j}$ respectively.

$$
\begin{aligned}
& X_{i}=\left\{X_{i}^{G}, X_{i}^{R}, X_{i}^{T}, X_{i}^{C}\right\} \\
& C_{j}=\left\{C_{j}^{G}, C_{j}^{R}, C_{j}^{T}, C_{j}^{C}\right\}
\end{aligned}
$$

where

$$
\begin{aligned}
X_{i}^{G}, X_{i}^{R}, X_{i}^{T}, X_{i}^{C} & \text { feature vectors of node } i \text { representing geographical location, risks } \\
& \text { facing, supply chain attributes and network connectivity attributes, } \\
& \text { respectively } \\
C_{j}^{G}, C_{j}^{R}, C_{j}^{T}, C_{j}^{C} & \text { centroids of cluster } j \text { representing geographical location, risks } \\
& \text { facing, supply chain attributes and network connectivity attributes, } \\
& \text { respectively. }
\end{aligned}
$$

Equations (1) and (2) are extended to incorporate different ways of evaluating centroids and squared errors for geographical location, risks facing, supply chain attributes and network connectivity attributes.

$$
\begin{aligned}
y_{i} & =\arg \min \left[w^{G}\left\|X_{i}^{G}-C_{j}^{G}\right\|^{2}+w^{R}\left\|X_{i}^{R}-C_{j}^{R}\right\|^{2}\right. \\
& \left.+W^{T}\left\|X_{i}^{T}-C_{j}^{T}\right\|^{2}+w^{C}\left\|X_{i}^{C}-C_{j}^{C}\right\|^{2}\right]
\end{aligned}
$$

where

$w^{G}, w^{R}, w^{T}, w^{C} \quad$ weightages for geographical location, risks facing, supply chain attributes and network connectivity attributes, respectively. $0 \leq w^{G}, w^{R}$, $w^{T}, w^{C} \leq 1$ and $w^{G}+w^{R}+w^{T}+w^{C}=1$.

Clustering results that draw special attention to some factors can be achieved through adjusting the weightages of the four factors. For example, by giving higher weightages to $w^{G}$ and $w^{R}$, such as 0.3 to 0.5 in our experiments, the supply chain nodes of the similar geographical location with higher risk scores can be identified. In this case, the nodes of a cluster may come from different supply chain tiers. However, by further emphasising the supply chain tier information and network connectivity, a group of nodes in geographically adjacent area with higher risk scores as well as providing similar components to the focal company can be recognised. Extra precaution could be arranged against such a cluster of nodes. By doing this, the disruptions such as Thailand flood during 2011 that resulted in a global shortage of hard disk supply due to the overly centralised hard disk manufacturers over the area could be better prepared and managed.

The optimisation criteria and updating of centroids are given by equations (6) to (10) respectively. 


$$
\begin{aligned}
& \arg \min \sum_{j=1}^{k} \sum_{i=1, y_{i}=j}^{n}\left[w^{G}\left\|X_{i}^{G}-C_{j}^{G}\right\|^{2}+w^{R}\left\|X_{i}^{R}-C_{j}^{R}\right\|^{2}\right. \\
& \left.+w^{T}\left\|X_{i}^{T}-C_{j}^{T}\right\|^{2}+w^{C}\left\|X_{i}^{C}-C_{j}^{C}\right\|^{2}\right] \\
& C_{j}^{G}=\sum_{i=1, y_{i}=j}^{n} X_{i}^{G} / n_{j} \\
& C_{j}^{R}=\sum_{i=1, y_{i}=j}^{n} X_{i}^{R} / n_{j} \\
& C_{j}^{T}=\sum_{i=1, y_{i}=j}^{n} X_{i}^{T} / n_{j} \\
& C_{j}^{C}=\sum_{i=1, y_{i}=j}^{n} X_{i}^{C} / n_{j}
\end{aligned}
$$

where

$n_{j} \quad$ number of nodes in cluster $j$.

By using an iterative refinement technique that mainly consists of two steps, assignment step [equation (5)] to determine the clusters and updating step [equations (7)-(10)] to determine the new centroids for the next iteration. The objective is to minimise the squared error represented by equation (6). It terminates when a fixed number of iterations defined by the user is reached or there is not change in cluster assignment between iterations.

\section{Experiments and discussions}

Three experiments have been used to illustrate the effectiveness of the proposed algorithm. As shown in Table 1, risks of a node facing consist of city risk and country risk; geographical location is represented by latitude and longitude; supply chain attributes include tier information. Transactional information and relative importance level between nodes can also be included as part of the supply chain attributes. As for risk scores of a city and its country, they have been normalised and the range is between 1 to 10 . Figure 4 illustrates how the connectivity of a network can be translated into multiple two dimensional matrix to be considered by k-means. By incorporating a scenario simulator that is able to define different sets of parameters, various supply chain clusters can be generated that emphases different concerned factors. It is able to form risk clusters of an entire supply chain that summarise the risks the supply chain of a company is exposing. It can also analyse the risk zones in respect to the geographical locations and raise alerts if critical facilities are all located in similar high risk zone. 
Table 1 Illustration of risks of a node, the geographical location, and supply chain attributes

\begin{tabular}{|c|c|c|c|c|c|c|}
\hline \multicolumn{3}{|c|}{ Geographical } & \multicolumn{3}{|c|}{ Risk score } & \multirow{2}{*}{$\begin{array}{l}\text { Tier } \\
\text { Type }\end{array}$} \\
\hline Node name & Latitude & Longitude & $\begin{array}{l}\text { Country } \\
\text { name }\end{array}$ & City risk & $\begin{array}{c}\text { Country } \\
\text { risk }\end{array}$ & \\
\hline $\begin{array}{l}\text { Ho Chi } \\
\text { Minh }\end{array}$ & 10.660608 & 106.61132 & Vietnam & 7 & 8 & Vendor tier 2 \\
\hline $\begin{array}{l}\text { Chiang } \\
\text { Mai }\end{array}$ & 18.7964642 & 98.6600586 & Thailand & 6 & 8 & Vendor tier 1 \\
\hline $\begin{array}{l}\text { Hong } \\
\text { Kong }\end{array}$ & 21.75 & 115 & China & 2 & 2 & Vendor tier 1 \\
\hline Qingdao & 36.066862 & 120.388184 & China & 6 & 6 & Vendor tier 1 \\
\hline Nanjing & 32.063956 & 118.78418 & China & 5 & 6 & Vendor tier 1 \\
\hline Bangkok & 13.752725 & 100.50293 & Thailand & 8 & 8 & Vendor tier 1 \\
\hline Chaling & 26.78129959 & 113.5406036 & China & 5.5 & 6 & $\begin{array}{l}\text { Manufacturing } \\
\text { plant }\end{array}$ \\
\hline Taizhou & 28.57500076 & 104.9091034 & China & 6.5 & 6 & $\begin{array}{l}\text { Manufacturing } \\
\text { plant }\end{array}$ \\
\hline Bangkok & 13.752725 & 100.50293 & Thailand & 8 & 8 & $\begin{array}{c}\text { Manufacturing } \\
\text { plant }\end{array}$ \\
\hline Singapore & 1.3581355 & 103.8191415 & Singapore & 3 & 3 & $\begin{array}{l}\text { Manufacturing } \\
\text { plant }\end{array}$ \\
\hline Singapore & 1.3581355 & 103.8191415 & Singapore & 3 & 3 & $\begin{array}{l}\text { Distribution } \\
\text { centre }\end{array}$ \\
\hline Brussels & 50.83710098 & 4.367599964 & Belgium & 5 & 5 & $\begin{array}{l}\text { Distribution } \\
\text { centre }\end{array}$ \\
\hline Lyon & 45.74710083 & 4.855400085 & France & 5 & 5 & Customer \\
\hline Marseille & 43.2845993 & 5.385099888 & France & 5 & 5 & Customer \\
\hline Paris & 48.88150024 & 2.432800055 & France & 5 & 5 & Customer \\
\hline Toulouse & 42.4530164 & -0.3275515 & France & 5 & 5 & Customer \\
\hline Ipoh & 4.609278 & 101.112671 & Malaysia & 5 & 6 & Customer \\
\hline
\end{tabular}

Figure 4 Illustration of network connectivity attributes (see online version for colours)

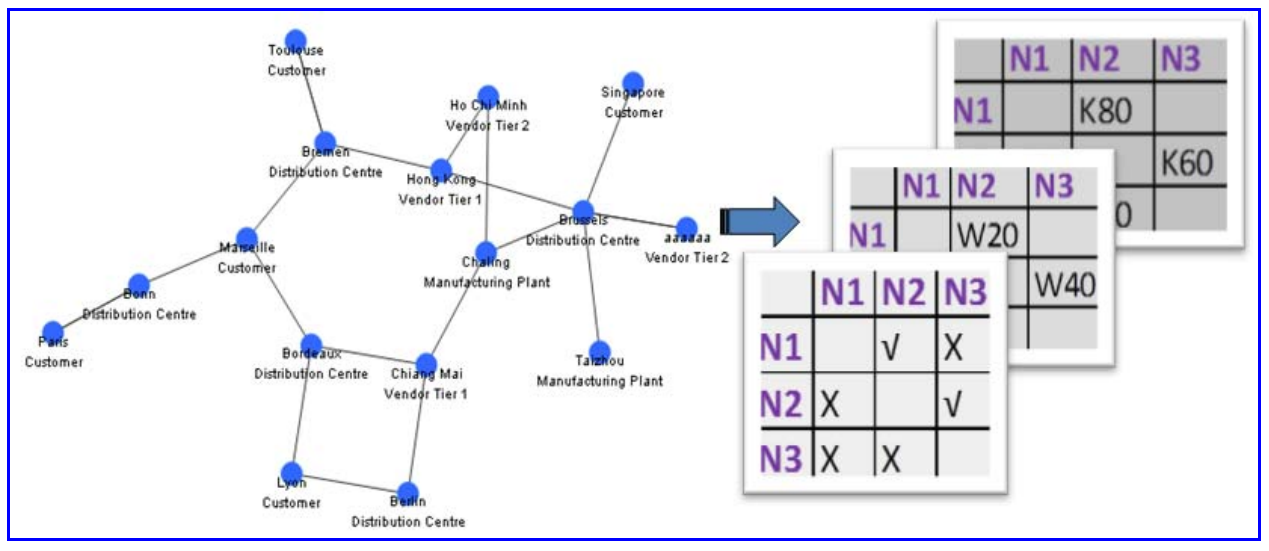




\subsection{Study1: risk cluster identification}

One of the purposes of the study is to find the high risk zone in respect to the risks nodes are exposing and the network connectivity. In the experiment, Thailand and its cities such as Bangkok and Chiang Mai are given high risk scores due to the past flooding issue and political unrest. Relatively high risk scores are configured for China and Vietnam owning to recent diplomatic and territorial disputes. As shown in Figure 5, the clustering algorithm partitioned the supply chain nodes into five categories that are identified in advance based on the predefined threshold. The threshold consists of both risk level the node is facing and the network connectivity representing the importance level of a node to other linked nodes. The details in clusters of very high risk and high risk (Figure 6) show the interconnected nodes located in Thailand, Vietnam and China. This illustrates that the clustering algorithm can work on not only the risk scores but also network connectivity that is critical in the context of supply chain management.

Figure 5 Supply chain risk clustering (see online version for colours)

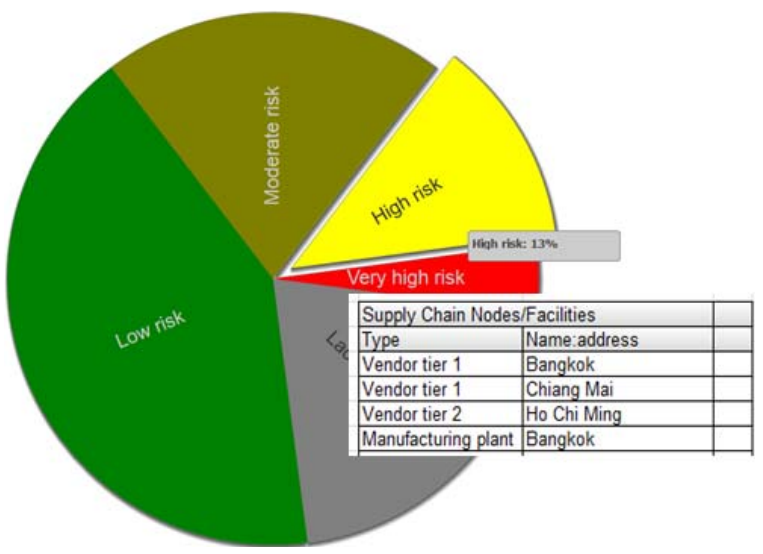

Figure 6 High risk nodes (see online version for colours)

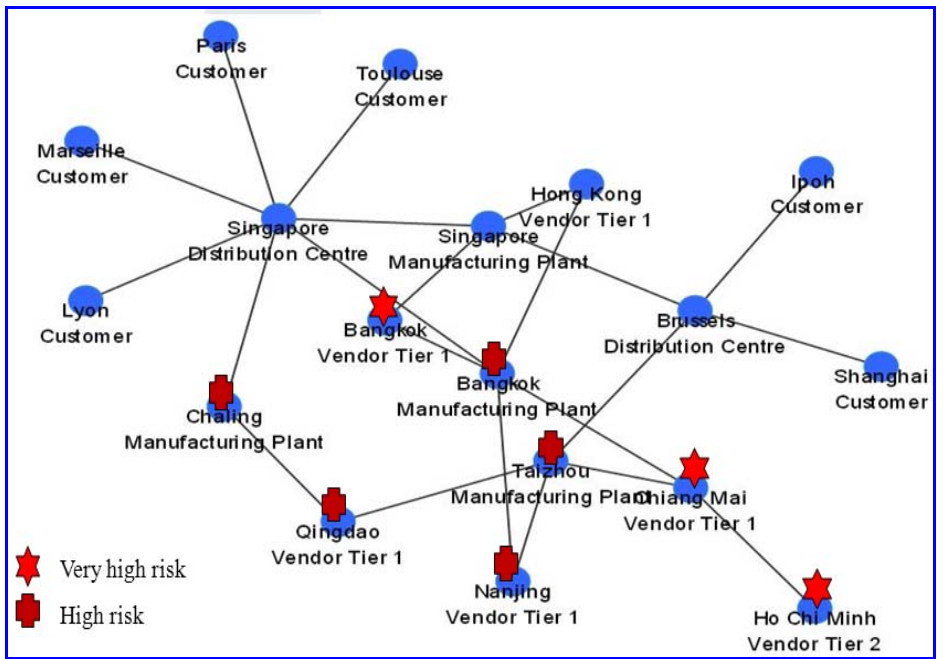




\subsection{Study 2: critical zoneclusteridentification}

In this experiment, parameters are tuned to emphasis more on the geographical locations besides the risk factors and the connectivity. The result is very similar as that from Study 1 except that the manufacturing plant in Bangkok has now been shifted into the very high risk cluster (Figure 7). It is due to the reason that Bangkok geographically is very close to other nodes in the very high risk cluster such as Ho Chi Minh and Chiang Mai. The change demonstrates that the geographical location plays a bigger role in this experiment. It is important to understand the risks a company is facing due to centralised suppliers and manufacturing facilities in different industrial sectors.

Figure 7 Critical nodes cluster (see online version for colours)

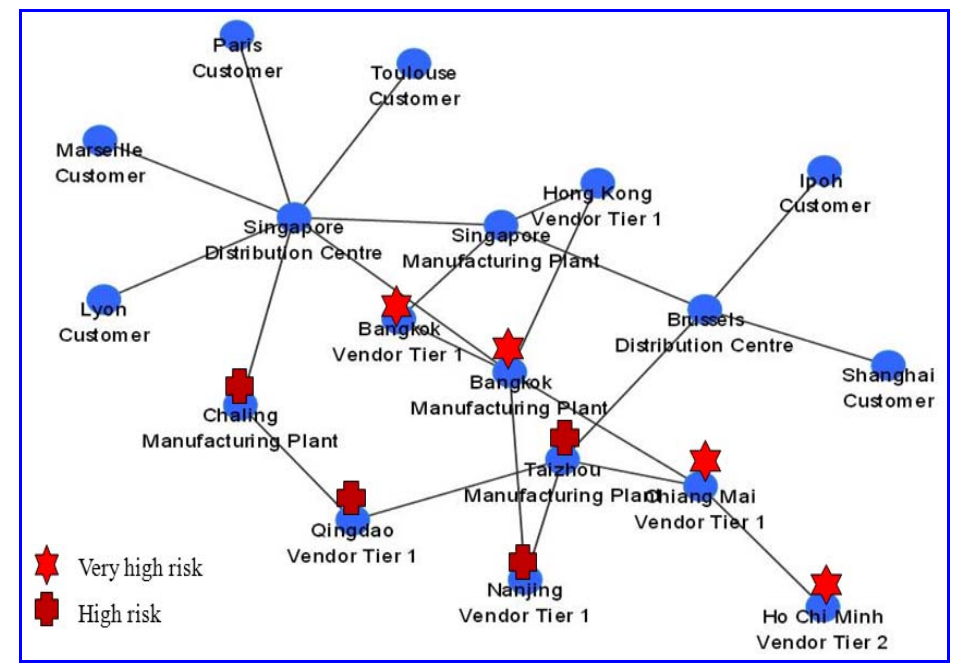

\subsection{Study 3: a larger scale supply chain network}

A more complete supply chain network with 180 nodes including 60 tier two vendors, 30 tier one vendors, ten manufacturing plants, four distribution centres and 50 customers is constructed to further illustrate the performance of the proposed approach. It is adapted from the supply chain structure (Willems, 2008) that represents 'game, toys, and children's vehicle'. With equal emphasis on the network connectivity, geographic location and supply chain attributes, a highest risk cluster with 32 nodes is formed. However there are eight nodes (four tier two vendors, two tier one vendors and two customers) that are isolated from others while the rest of the supply chain nodes in the cluster are well connected. The reason of existence of those isolated nodes in the cluster is mainly due to that they are located in the highest risk zones. As the network connectivity and geographical location is not playing a significant role in the configuration, geographically non-adjacent or disconnected nodes might be grouped together. While with more emphasis on the network connectivity, the formation of the highest risk cluster is changed. The eight isolated nodes are removed and a fully connected sub-network is formed within the cluster. Instead of individual node assessment, the supply chain risk clustering provides a more holistic view on the 
configuration of the high risk sub-network. The production and products that potentially could be affected by the risky sub-network can then be identified. Targeted measurements, analysis and simulations can be designed and employed to the specific cluster of the supply chain and efforts for preparation of potential disruptions can be better managed and distributed.

\section{Conclusions and future work}

The main purpose of this work is to illustrate the value of supply chain risk clustering and how the connectivity of network could be embedded that can further enhance the clustering. In this study, a network connectivity embedded k-means clustering approach has been proposed. The proposed approach is able to determine groups of 'similar' nodes that can be used as a basis for tactic and strategic risk management of the entire supply chain. The following two scenarios have been demonstrated in the experiments:

1 risk cluster identification that is able to identify nodes with high dependencies and high risk scores

2 critical nodes located in similar geographic location that is prone to certain risk or disruption.

The use of squared errors in the objective function has its own limitations in incorporating network/graph features such as network flows into k-means. Further research needs to be carried out to extend the model to a complete set of network features. In addition, different clustering and classification algorithms such as fuzzy c-means and neural network will have to be examined. Through these further researches, we can enhance the performance of clustering as well as to reduce the number of predefined parameters such as weightages of different factors and number of clusters. A more complex supply chain network will then be used to carry out the study for further enhancements of the proposed algorithm.

\section{References}

Bearzotti, L.A., Salomone, E. and Chiotti, O.J. (2012) 'An autonomous multi-agent approach to supply chain event management', International Journal of Production Economics, Vol. 135, No. 1, pp.468-478.

CFO Research Services (2013) Preparing for the Worst: Natural Disasters and Supply-Chain Risk Management [online] http://www.fmglobal.com/assets/pdf/P09179.pdf (accessed 8 May 2013).

Doring, A., Wilhelm, D. and Christoph, D. (2007) 'Using k-means for clustering in complex automotive production systems to support a Q-learning-system', IEEE ICCI 2007, pp.487-497.

Hallikas, J., Puumalainen, K., Vesterinen, T. and Virolainen, V. (2005) 'Risk-based classification of supplier relationships', Journal of Purchasing and Supply Management, Vol. 11, Nos. 2-3, pp.72-82.

Hu, J., Hua, E., Fei, Y. and Chen, D. (2009) 'Research of neural network based on fuzzy clustering in supply chain quality affecting elements data mining', International Conference on Management and Service Science, 2009. MASS '09, pp.1-5. 
Irfan. D., Xu, X., Deng, S. and Khan, I.A. (2007) 'Clustering framework for supply chain management (SCM) system', Second Workshop on Digital Media and its Application in Museum \& Heritage, IEEE 2007, pp.422-426.

Reniers, G.L.L., Sorensen, K. and Dullaert, W. (2012) 'A multi-attribute systemic risk index for comparing and prioritizing chemical industrial areas', Reliability Engineering and System Safety, Vol. 98, No. 1, pp.35-42.

Tabrizi, B.H. and Razmi, J. (2013) 'Introducing a mixed-integer non-linear fuzzy model for risk management in designing supply chain networks', Journal of Manufacturing Systems, Vol. 32, No. 2, pp.295-307.

Tang, C.S. (2006) 'Perspectives in supply chain risk management', International Journal of Production Economics, Vol. 103, No. 2, pp.451-488.

Tang, O. and Musa, S.N. (2011) 'Identifying risk issues and research advancements in supply chain risk management', International Journal of Production Economics, Vol. 133, No. 1, pp.25-34.

Thun, J.H. and Hoenig, D. (2011) 'An empirical analysis of supply chain risk management in the German automotive industry', International Journal of Production Economics, Vol. 131, No. 1, pp.242-249.

Willems, S.P. (2008) 'Real-world multi-echelon supply chains used for inventory optimization', Manufacturing \& Service Operations Management, Vol. 10, No. 1, pp.19-23.

Yin, X.F., Fu, X.J., Ponnambalam, L. and Goh, S.M. (2015) 'A network connectivity embedded clustering approach for supply chain risk assessment', Proceedings of the 18th Asia Pacific Symposium on Intelligent and Evolutionary Systems, pp.389-396.

Yin, X.F., Khoo, L.P. and Chong, Y.T. (2013) 'A fuzzy c-means based hybrid evolutionary approach to the clustering of supply chain', Computers \& Industrial Engineering, Vol. 66, No. 4, pp.768-780. 